\title{
El rol de los códigos no verbales de la realidad en la creatividad del discurso publicitario
}

\section{The role of nonverbal codes of reality on the creativity of advertising discourse}

Carlos Fanjul Peyró. Universitat Jaume I

Cristina González Oñate. Universitat Jaume I

Recibido: 4-II-2011 - Aceptado: 14-IX-2011

Resumen:

El presente artículo supone una reflexión sobre la importancia y riqueza que posee la comunicación no verbal dentro del mensaje publicitario, tanto para la recreación de la historia comercial, como para la elaboración de los mensajes connotados que en ella se esconden y para la configuración del significado y sentido final con el que se quiere fraguar la pieza publicitaria. Los creativos publicitarios tienen la función de estudiar, conjugar e imbricar en sus piezas todos estos elementos no verbales, con el objetivo de dotar al producto/marca anunciado de diferenciación, atractivo y personalidad. Esta labor determinará el resultado final creativo e influirá en la eficacia, pertinencia, aceptación y repercusión del anuncio, del producto/marca y de los valores e ideales vinculados al mismo.

Palabras clave:

Publicidad, Creatividad, Comunicación no verbal, Códigos no verbales de la realidad, Lenguaje publicitario Abstract:

This article is a reflexion on the importance and richness that have nonverbal communication within the advertisement, both for the recreation of commercial history and for the preparation of messages that it connoted hide and the configuration of the meaning and sense of the advertising piece. Advertising creatives have the task of studying, combine and merge in their pieces these nonverbal elements, with the aim of providing differentiation, attractiveness and personality to the product/brand announced. This work will determine the final creative outcome and it will influence on effectiveness, relevance, acceptance and impact of the advertisement, the product/brand and the values and ideals associated with it.

Keywords:

Advertising, Creativity, Nonverbal Communication, Nonverbal codes of reality, Advertising language 


\section{Introducción}

El discurso publicitario hace uso de todos los componentes de la comunicación para elaborar sus mensajes buscando siempre objetivos de información, persuasión y seducción. Este entramado de la comunicación comercial provoca que los creativos publicitarios estudien, trabajen y construyan los códigos verbales y no verbales del mensaje para conseguir influir y atraer al receptor, tanto en sus propuestas explícitas (denotadas) como implícitas (connotadas).

En una sociedad como la actual, dominada por la imagen y la simbología, se hace necesaria una mayor atención y un exhaustivo estudio sobre la capacidad de significancia (entendida como la construcción del sentido) de los textos y mensajes icónicos. Principalmente, son estas cuestiones las que impulsaron los estudios semióticos de la imagen, que encontraron un atractivo filón de investigación dentro del campo publicitario (Bianchi, 2011).

Para persuadir a los consumidores, la publicidad enmascara la "frialdad" de los bienes industriales a través de un contexto que connota y transfiere al producto y a su consumo, un status, unos valores y una imagen que objetivamente no posee. Los anuncios crean un mundo imaginario alrededor del producto, de manera que su compra "da derecho" a entrar (imaginariamente) en ese mundo. Ese contexto en el que la publicidad envuelve sus productos, esos valores, ideales, emociones, esa referencia subjetiva que la publicidad confiere al producto para diferenciarlo y persuadir al consumidor, viene dado, en la mayoría de los casos, en el mensaje connotado, latente, de la publicidad. Y es la comunicación no verbal la principal portadora de esta significación.

La comunicación publicitaria, al tratar de simular o recrear en la mayoría de sus piezas, situaciones o historias en las que participan personas que interactúan (bien entre sí o bien con el espectador-receptor), plasma y hace uso de la comunicación no verbal humana en la elaboración de sus mensajes. Los códigos no verbales de la realidad (kinésica, proxémica, paralenguaje, atractivo físico...) juegan un papel decisivo en este proceso de significancia y son especialmente estudiados y considerados por el creativo publicitario para imbricar connotativamente valores, ideales y modelos de conducta que personalicen, diferencien y hagan atractivo al producto/marca que publicitan.

\section{La capacidad de significancia en el discurso publicitario}

Los primeros pasos de aproximación a la lectura y análisis de la imagen publicitaria los hallamos de la mano de la semiótica. Autores como Péninou (1976), Moragas (1976) o Eco (1978) esbozan en sus estudios la capacidad de significancia de la composición icónica del mensaje publicitario. La significación (entendida como la relación entre un significante y un significado) se produce gracias al proceso de significancia que es definida por Eguizábal y Caro (2000) como el efecto de sentido que se produce por el juego de los significantes dentro de un enunciado. "No se trata de realizar una combinación 
u ordenación mecánica de los elementos, sino de una fusión, de lograr que el conjunto sea superior, diferente a la suma de las partes y que tenga significación" (García, 2003: 17).

La semiótica nace de la mano de Charles Sanders Peirce y, aunque guarda principios comunes con la semiología de Saussure (corriente europea), esta se distancia de su homóloga tanto en su concepción del signo como en la del significado. Peirce (1986) define el signo según una triple relación (signos de sí mismos, signos en relación al objeto y signos en relación con el sujeto) que da lugar a la triple distinción en el lenguaje entre sintáctica, semántica y pragmática. En función de esta tríada relacional, la concepción de "significado" se modifica en cuanto que éste dependerá del marco en el que se dé la situación comunicativa y de la experiencia sociocultural de los actantes. El contexto y las circunstancias que rodean el acto de comunicación son tenidos en cuenta por la semiótica por su papel determinante en la creación del sentido.

Trasladando los principios de la semiótica al campo publicitario, esta iría más allá del estudio de las funciones de la imagen y lo que buscaría sería investigar y profundizar el modo de producción de sentido. La semiótica publicitaria estudiaría la manera en que los mensajes comerciales provocan significaciones, es decir, interpretaciones. "En efecto, un signo no es ‘signo' si no 'expresa ideas', si no provoca en el ánimo de quien o de quienes lo perciben una tarea interpretativa” (Joly, 1999: 32).

Tal y como establece Leduc (1986), el lenguaje de la publicidad es el lenguaje del deseo, de la persuasión, de la seducción. En sus mensajes trata de reflejar lo que quisiéramos ser o tener. Para ello utiliza diversos recursos verbales, icónicos y musicales, que configuran un texto pragmático cuya eficacia consiste en hacernos una gran promesa. La publicidad habla de un producto, marca o idea (mensaje denotado), pero no de una forma objetiva ni exhaustiva, sino buscando llamar la atención sobre aquello que pueda despertar la sensibilidad del consumidor. Así, este producto, marca o idea se constituye en el significante de un segundo mensaje (connotado) que asocia valores e ideales y configura el verdadero sentido y significado del discurso publicitario. La creación y vinculación entre los valores de uso de un producto (generalmente denotados) y los valores de base del mismo (generalmente connotados) es lo que caracteriza al lenguaje publicitario y por lo que convierte a esta técnica de comunicación en objeto de interés para la semiótica.

Rodríguez y Mora (2002) enfatizan en su obra Frankenstein y el cirujano plástico: una guía multimedia de semiótica de la publicidad, el concepto de intertextualidad aplicado al campo publicitario. Este término hace referencia a que todo texto ${ }^{1}$ presente está siempre interrelacionado y conectado con otros textos latentes (ausentes) que configuran y determinan el sentido y significación global-final del mensaje.

1 Interprétese el concepto "texto" como todo tipo de mensaje, ya sea audiovisual o literario. 
Todo texto es un intertexto; otros textos están presentes en él, en estratos variables, bajo formas más o menos reconocibles; los textos de la cultura anterior y los de la cultura que los rodea; todo texto es un tejido de códigos, fórmulas, modelos rítmicos, segmentos de lenguas sociales, etc., pues siempre existe el lenguaje antes del texto y a su alrededor. La intertextualidad, condición de todo texto, sea éste cual sea, no se reduce como es evidente a un problema de fuentes o de influencias; el intertexto puede ser también un campo general de fórmulas anónimas, cuyo origen es difícilmente localizable, de citas inconscientes o automáticas, ofrecidas sin comillas (Rodríguez y Mora, 2002: 41).

La semiótica de la narrativa publicitaria ha puesto en evidencia la existencia de estructuras profundas que organizan el discurso creativo, verbal y/o no verbal, comercial. En este contexto, la publicidad se concibe como un mapa de relaciones donde se entrelazan y se complementan signos, registros y códigos provenientes de distintos campos (humano, audiovisual, literario, imaginario...) que, como en una orquesta, confluyen y generan una única pieza final cargada de sentido y significado propio y que no se entendería si se analizasen de forma independiente cada una de sus partes (Bianchi, 2011).

\section{Códigos no verbales en la publicidad}

Los códigos son el instrumento que permite establecer una correspondencia común entre significantes y significados y que permiten determinar, comprender y descifrar el proceso de significancia que enlaza los distintos significantes hacia un sentido y valor determinado. La exhaustividad en el estudio de los elementos que constituyen cada uno de esos códigos y su interrelación garantizará una mayor y mejor comprensión de cuestiones tales como la intencionalidad del mensaje, influencia o repercusión, tanto en lo referente a cuestiones estrictamente comerciales como sociales y culturales. El análisis de la publicidad debe comprender el estudio de todos los componentes del mensaje (verbales y no verbales) que hacen posible y confieren esa significación, ya que obviar alguno de ellos podría desvirtuar y modificar los resultados de su investigación.

Para conseguir su significación global, la publicidad se sirve de los códices propios del lenguaje fílmico, dentro de los cuales podemos distinguir entre códigos de la realidad, códigos del discurso y códigos ideológicos. Los primeros hacen referencia a aquellos que se vinculan directamente con el ser humano y que comprenderían tanto los códigos verbales (discurso de los sujetos en escena) como los no verbales (gestos, expresión facial, apariencia física, posturas, etc.). Por códigos del discurso se entienden todos aquellos elementos propios del lenguaje audiovisual (encuadres, planos, tomas, iluminación, movimientos de cámara...). Y, finalmente, los ideológicos serían aquellos códigos simbólicos tomados del sistema social y cultural, que engloban y organizan tanto a los códigos de la realidad como del discurso (valores, estilos de vida) (Metz, 2001; Cassetti y Di Chio, 1999). 
La conjunción de elementos verbales y no verbales de la comunicación humana, de componentes no verbales del discurso y de los factores simbólicos del mensaje, constituirán el lenguaje publicitario y dotarán, en su conjunto, de pleno sentido y significado al anuncio. El estudio del producto y la marca, la personalidad de la empresa anunciante, el análisis del mercado, los objetivos a alcanzar, las características del público, las motivaciones de éstos y un largo etcétera, serán aspectos claves que deberán ser tenidos en cuenta a la hora de dar forma a la pieza creativa publicitaria y que jugarán un papel esencial en aspectos como el contexto en el que se enmarca el anuncio, selección de actores, determinación de voces, elaboración de textos, diseño gráfico, colores, elección de ilustraciones y fotografías... Los creativos, con la conjunción de todos estos elementos, irán forjando el sentido global, la interpretación y la significación pretendida del anuncio. La creatividad en la fusión de estos códigos de la realidad, del discurso e ideológicos en una pieza con una concepción global, enriquece y amplia las posibilidades y capacidades comunicativas de los mensajes publicitarios. Todo ello determinará el resultado final creativo e influirá en la eficacia, pertinencia, aceptación y repercusión del anuncio, del producto/marca y de los valores e ideales vinculados al mismo.

\section{El rol de los códigos no verbales de la realidad en la creatividad publicitaria}

La falta de diferenciación, el crecimiento de la competencia, la búsqueda de una personalidad propia de producto y marca, la necesidad de forjarse un hueco en el mercado y en la mente del consumidor, provoca que los anunciantes (empresas) soliciten y exijan a su publicidad crear un "objeto semiótico" a expensas de su "objeto económico". Bassat (1993) argumenta que, en esa situación de saturación e indiferenciación de productos y mercados, con un consumidor cada vez más exigente e informado, las decisiones de compra se rigen más por cuestiones pasionales que racionales. En los países más desarrollados, el consumo se ha convertido, más que una actividad económica, en un rito simbólico, una actividad social y comunicativa que comporta una carga de significado, una construcción de sentido.

La publicidad es una comunicación persuasiva y, como tal, su principal objetivo va a ser siempre convencer; convencernos sobre un producto, servicio o idea, pero también de valores socialmente correctos, modas, cánones, etc. La publicidad crea, a través de los valores que connota a sus productos, modas, mitos o fetiches en los que los individuos ven un reflejo, un ideal o un potencial.

Los consumidores ya no adquieren muchos productos por lo que es el producto en sí, sino por la imagen y valores simbólicos que el producto conlleva. La homogeneización de los productos, que se produce en los mercados de consumo, y las dificultades para la diferenciación con respecto a la competencia, hace que las empresas busquen la diferenciación a través de esos valores simbólicos de sus productos. La competencia entre los productos de consumo se ha convertido más bien en un concurso entre los símbolos o imágenes competitivas que entre los valores materiales. 
La combinación de posicionamiento y diferenciación otorgan a la marca o producto su carácter específico, es decir, su personalidad propia. La personalidad, como en las personas, es lo que hace a un producto diferente de los demás, y lo que genera actitudes positivas o negativas hacia el mismo. Conseguir un posicionamiento, una diferencia y una personalidad positiva para los objetos que se anuncian es la principal tarea del profesional de la comunicación. "No aceptamos a las personas. Lo que aceptamos es su personalidad. Y del mismo modo, no compramos marcas o empresas. Compramos porque aceptamos su personalidad. A veces, por un aspecto muy acentuado de su carácter: un beneficio o una ventaja concreta" (Lorente, 1991: 25).

Ante esta situación, la creatividad publicitaria busca encontrar en la elaboración de sus piezas aquellos aspectos que hagan al producto o servicio distinto de la competencia y que, a su vez, personalicen y den notoriedad a la marca. Para conseguirlo, pone el énfasis en otro tipo de beneficios que van más allá del bien anunciado, apoyándose para ello más en la forma que en el contenido del mensaje. La publicidad mediada se va transfigurando así de una publicidad referencial (dirigida de forma más racional sobre el objeto anunciado y sus características) hacia una publicidad relacional (dirigida hacia la parte más emocional vinculando valores, ideales, símbolos... al producto y su consumo).

Las estrategias retóricas y seductoras de la comunicación publicitaria deben gran parte de su capacidad a los códigos no verbales de la realidad ${ }^{2}$. La persuasión y la seducción del anuncio vienen conferidas, mayoritariamente, por un compendio de elementos de naturaleza no verbal que intervienen en el mensaje y que le confieren su sentido, significación y valor influyendo en su eficacia, repercusión y recuerdo. El estudio y análisis de estos factores en la investigación de la comunicación publicitaria se convierte así en un elemento clave, ya no solo para comprender el fenómeno y el entramado publicitario en su globalidad, sino también para determinar la influencia de los mismos en ámbitos fuera de su vertiente económica (ventas) como pueden ser sus repercusiones sociales y educativas.

La comunicación no verbal, empleada como recurso del lenguaje publicitario, influye de forma determinante en la formación del mensaje connotado y en la vinculación de éste al producto o marca anunciado. Sin embargo, genera prácticas fraudulentas de la comunicación humana, ya que la espontaneidad que marca y caracteriza a la información emocional, desaparece. Es decir, que la mayoría de los elementos de comunicación no verbal que encontramos en la publicidad, han sido previamente estudiados y analizados para transmitir un mensaje concreto y conseguir su objetivo. Existe, por tanto, una pérdida de la inocencia o una falsa espontaneidad de la comunicación no verbal. "En la publicidad, bien sea como acción o como reacción, el mensaje no verbal fluye inmediatamente y de forma espontánea, aunque tal naturalidad esté muchas veces controlada" (Pérez, 1979: 271).

1 Las áreas de estudio que abarcan estos códigos serían: la kinésica, la proxémica, los factores del entorno, la cronémica, las características físicas, los artefactos, el paralenguaje, la conducta visual, la comunicación por el tacto y la comunicación por el olfato. 
Las historias publicitarias protagonizadas por hombres y/o mujeres exigen este especial cuidado en la construcción y selección de los códigos no verbales de la realidad que van a formar parte del anuncio. Las características y atractivo físico de los personajes, sus gestos, los artefactos que portan o manipulan, las distancias que guardan entre ellos, el contexto donde se enmarca la historia publicitaria y un largo etcétera, son componentes no verbales de la realidad que no se dejan al azar ni se eligen de forma altruista en los mensajes publicitarios. Detrás de cada uno de estos elementos hay todo un proceso de producción responsable y encargado de la selección de modelos, casting, puesta en escena, atrezzo... Implica muchas horas de trabajo y una gran labor profesional en la que se busca adecuar lo más posible los aspectos no verbales que se van a proyectar en la historia que se va a narrar en el anuncio, a la personalidad, valores y seducción con la que se va a dotar al producto o marca anunciada.

\section{Un estudio experimental: objetivos e hipótesis}

El objetivo de este artículo y el siguiente análisis, no es otro que el de comenzar a plantear una reflexión sobre la importancia y riqueza que posee la comunicación no verbal dentro del mensaje publicitario, tanto para la recreación de la historia comercial, como para la elaboración de los mensajes connotados que en ella se esconden o para su utilización como estrategia comunicativa diferencial. La pretensión del trabajo aquí expuesto, no es el de plantear conclusiones definitivas con vistas a extrapolarlas a todas las campañas que se realizan bajo esta estrategia. Sin embargo, con ello sí que se pretende llamar la atención de los investigadores sobre el importante rol que la comunicación no verbal puede desempeñar en el mensaje publicitario y destacar su capacidad de comunicación hasta el punto de poder fundamentar toda una estrategia comunicativa en la misma.

Este trabajo parte con la hipótesis principal de que la publicidad audiovisual utiliza y estudia elementos propios de la comunicación no verbal humana para configurar y conferir a sus mensajes comerciales valores connotados (subjetivos) que dotarán al producto/marca anunciado de una personalidad propia. Como en las personas, la personalidad publicitaria es lo que hace a un producto/marca diferente de los demás, y lo que genera actitudes positivas o negativas hacia el mismo.

Como planteamiento derivado, también se considera que los spots que se apoyan en la no verbalidad para "narrar" sus historias, la utilizan como estrategia diferencial que constituye un arma de imagen y una posible salida, para llamar la atención, evitar la saturación o el descenso de efectividad que se puede dar en la publicidad televisiva y perdurar en el imaginario colectivo.

\subsection{El análisis de dos casos: Martini y Loterías y Apuestas del Estado}

Para desarrollar una aproximación a la aplicación práctica de todo lo expuesto anteriormente, se analiza el rol que algunos códigos no verbales de la realidad desempeñan en la estrategia, creación y diseño de tres anuncios publicitarios; dos 
spots pertenecientes a la campaña de "Martini Dream" (1995-1998) y un spot de la campaña de "Lotería de Navidad" de Loterías y Apuestas del Estado (1998-2005).

La compañía Bacardí-Martini lanzó en 1995 una campaña de publicidad para Martini presentando al "Hombre Martini” y sus aventuras como la esencia del estilo de vida en la Riviera de los 60. A través de películas en blanco y negro, con reminiscencias de ese período, la campaña propone este nuevo y sugerente símbolo para su vermut y lo lanza a través de una serie continuada de episodios provocativos. Se analizan dos spots de esta campaña de Martini por ser una de las primeras marcas que apostó por la aplicación y utilización de elementos propios de la comunicación no verbal en la estrategia, creación y diseño del mensaje publicitario y cuya eficacia, tanto en recuerdo de marca como en ventas, ha quedado más que demostrada.

Dentro del campo de la publicidad televisiva que ha utilizado de forma exclusiva y exitosa la comunicación no verbal como estrategia, se ha escogido la campaña que entre los años 1998 y 2005 llevó a cabo la entidad pública Lotería y Apuestas del Estado, por basar prácticamente todos sus anuncios en este tipo de comunicación, utilizándola tanto como recurso como estrategia diferencial publicitaria. De todos los spots pertenecientes a esta campaña, se ha seleccionado el último que se emitió con "el Calvo de la Lotería" como protagonista en el año 2005, por seguir con la estrategia no verbal como eje de comunicación y por ser fiel reflejo de sus predecesores (en planteamiento y formato), aunque adoptando en su elaboración un elemento que, hasta el spot del año anterior (2004), los otros no poseían: el uso del color como parte de la narrativa audiovisual.

La utilización del blanco y negro en los primeros spots, respondía a una estrategia no verbal de diferenciación; generalmente, la mayoría de los anuncios que se pasan por televisión son en color, pero además, en la época del año en la que se emite la campaña de "Lotería de Navidad" (noviembre y diciembre), la publicidad en televisión suele estar más sobrecargada del colorido típico de las fechas (rojos, verdes, dorados). En este último anuncio con el "Calvo de la Lotería”, se vuelve a utilizar el blanco y negro en parte del anuncio, evocando así a las historias presentadas en años anteriores y manteniendo la idea original con la que se fraguó la campaña. Sin embargo, en un momento dado el blanco y negro da paso al color. Este cambio queda justificado por el propio desarrollo de la historia publicitaria, ya que como se verá en el análisis, el blanco y negro es utilizado en la parte del spot que transcurre en un contexto de tiempos pasados y el color aparece cuando el personaje principal entra en la época actual.

Utilizando el análisis de contenido como metodología de estudio y tomando como unidad de análisis el plano, se estudian cualitativamente los parámetros de "expresión facial", "proxémica” y "aspecto físico-artefactos" en dos spots de la campaña "Martini Dream" (1995) y en el spot “Lotería de Navidad 2005” de la campaña navideña de Loterías y Apuestas del Estado. Se trata de unos ejemplos de gran riqueza en códigos no verbales de la realidad, ya que la principal característica de estas campañas es la ausencia de comunicación verbal en sus anuncios para televisión.

\section{2 | no 14 | doxa.comunicación}


De la expresión facial se analizan las emociones manifestadas por los principales protagonistas de los spots, sus gestos y las posibles significaciones y connotaciones que pretenden transmitir con ellos. Dentro de la proxémica se estudian tanto las distancias entre los personajes (y las implicaciones que conllevan las mismas) como la ambientación y distribución de espacios. Finalmente, en el área del aspecto físico-artefactos se analiza el rostro, la complexión corporal, su proporción y los artefactos que portan (ropa y complementos).

Para el análisis de la expresión facial se tomaron como referencia los estudios de Ekman y Friesen (1969, 1971) que dividen el estudio del rostro en tres zonas: cejas/frente, ojos/párpados/área del caballete de la nariz y mejillas/nariz/ boca/mentón/mandíbula. Considerando estas tres áreas, se analiza la emoción expresada por el personaje, así como sus gestos (siguiendo los estudios de Birdwhistell(1952) y de la obra Diccionario de Gestos de Meo-Zilio y Mejía (1980) y las posibles significaciones y connotaciones que se pretenden transmitir.

Dentro de la proxémica, se estudian tanto la distancia entre los personajes como la ambientación y distribución de espacios. En función de las investigaciones de Hall $(1989,1972)$ se analizan, sobre las distancias, qué relaciones se establecen entre los personajes y qué implicaciones conllevan las mismas; y respecto a la distribución del espacio se estudia si ésta dificulta o favorece la interacción y qué implicaciones comunicativas posee.

Las obras de Mills y Aronson (1965), Knapp (1995), Sheldon (1954) y Gubern (1998) son tomadas como base de análisis en el área del aspecto físico-artefactos en los spots. Se estudia, de los personajes, el rostro, la complexión corporal, su proporción y los artefactos que portan (ropa y complementos) para determinar los estereotipos mostrados, la correspondencia de determinados personajes con los cánones de belleza actual y la definición del rol y estatus a través de los artefactos de los personajes.

\subsubsection{Martini}

En el estudio de los spots de la campaña Martini Dream, se definen un total de 46 planos para el spot "el hombre Martini en la Riviera" y 32 para "el hombre Martini en el Casino". Ambos cuentan con una estructura formal idéntica respondiendo al esquema narrativo de planteamiento-nudo-desenlace. El planteamiento se construye con la aparición de un personaje misterioso (hombre Martini) que se aproxima a una situación dada (terraza en la Riviera, mesa de juego en el Casino). El nudo comienza cuando el hombre Martini irrumpe en esa situación y lanza "un reto" (te invito a beber Martini) a la mujer que desea seducir. Este reto está rodeado de una situación tensa (intentar seducir a la chica del "mandatario" o una apuesta). El desenlace siempre supone el triunfo del hombre Martini (un final feliz). Los personajes de la historia son clasificados, siguiendo la propuesta de Piñuel y Gaitán (1995), en: el mandatario (hombre poderoso), el héroe (hombre Martini), la princesa (chica seducida) y el auxiliar mágico (Martini). 
Una vez desglosados los dos spots del hombre Martini en sus diferentes planos y analizadas las variables de estudio de la comunicación no verbal seleccionadas, se concluye que la proxémica de los spots aporta información, tanto de las relaciones que se establecen entre los protagonistas (relación afectiva (mandatario-mujer), relación laboral (camareros, guardaespaldas, croupier), relación de deseo (hombre Martini-mujer), etc.), como de la actitud que adopta el héroe (hombre Martini) con respecto al resto de protagonistas del spot (distanciamiento del hombre poderoso, posición frente a frente respecto a la chica al "lanzar el reto", reducción de la "distancia psicológica” entre el hombre Martini y la chica a través de las miradas, proximidad física con la mujer al final del spot). Las distancias entre los personajes se establecen siempre mediando entre ellos un objeto (mesa). Éste sirve a los personajes de "parapeto" o "refugio", lo cual les puede permitir una mayor seguridad en sus acciones. Sobre este objeto, siempre está presente la botella de Martini, que es el intermediario entre el hombre Martini y las mujeres.

En los dos casos estudiados, el hombre Martini se introduce en un territorio que los otros personajes podrían sentir como propio (la mesa en la terraza de la Riviera o la mesa del Casino). Cuando el hombre Martini entra en el territorio de los otros personajes provoca reacciones antagonistas en ellos: de agrado para las mujeres y de desagrado para los hombres. Además, el protagonista siempre adopta una disposición frente a frente con la chica a conquistar, ya que esta situación es considerada como la más favorable para una acción de seducción.

Respecto a las expresiones faciales se observa como estas son las que llevan el peso narrativo del anuncio informando sobre emociones, intenciones y "diálogo" que van desarrollando los protagonistas. Teniendo en cuenta que los personajes que se nos muestran en las historias de Martini son ficticios (actores representando un papel) no sorprende que las expresiones faciales sean fácilmente identificables y codificables ya que se trata de expresiones trabajadas que buscan comunicar de una forma directa y clara una emoción o un estado de ánimo. Las principales expresiones identificadas en los spots de Martini son: la sorpresa, la rabia/disgusto, el deseo/seducción, la dureza/seguridad, el agrado y el interés/curiosidad.

Tabla I. Expresiones identificadas en los spots de Martini

\begin{tabular}{|c|c|}
\hline Expresión & Número de veces identificada \\
\hline Sorpresa & 7 \\
\hline Rabia/disgusto & 4 \\
\hline Deseo/seducción & 4 \\
\hline Dureza/seguridad & 4 \\
\hline Agrado & 3 \\
\hline Interés/curiosidad & 3 \\
\hline
\end{tabular}

Fuente: Elaboración propia. 
Los gestos de los personajes ayudan, tanto a definir las emociones e intenciones de los mismos, como a mantener el hilo de la "narración" visual. El principal gesto analizado (ya que es el más característico del protagonista y fue el que más trascendió al público final) es el que realiza el hombre Martini cuando se pasa el dedo pulgar barriendo sus labios carnosos.

Figura 1. El gesto Martini

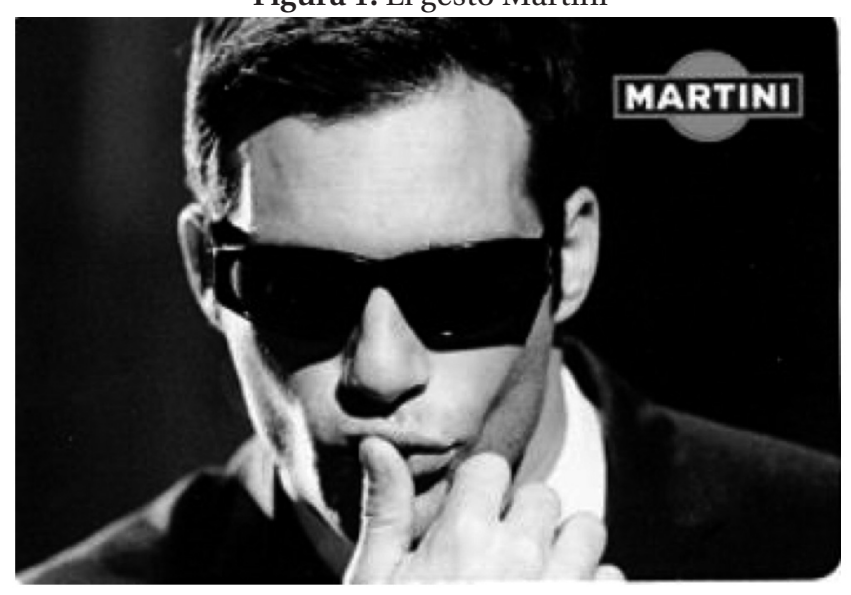

Fuente: Imagen extraída del spot “El hombre Martini en el Casino”

El hombre Martini utiliza este gesto para seducir a las mujeres que provoca. Tiene una carga sensual y erótica que conquista. Pero además existe una gran similitud entre este gesto y el que se utiliza en los países hispanos como indicativo del "número uno". Por tanto, se puede decodificar este gesto tanto como elemento de seducción como indicativo de superioridad ("soy el número uno"). El "gesto Martini" caló socialmente y fue muy aceptado e imitado. Es un gesto de carácter sensual y seductor que consiguió ser bien identificado y aceptado por los receptores de la campaña. Martini logró así crear un emblema vinculado directamente con su marca.

Otros gestos que se identifican en el estudio de los spots y que ayudan al desarrollo y comprensión de la historia son: señalar con el gesto índice (gesto deíctico que indica dirección y centra la atención); enarcar una ceja (gesto de sorpresa, intriga o duda); negar (movimiento oscilante horizontal de la cabeza); acariciar la barbilla (expresa interés, concentración o apreciación de lo bueno).

Finalmente, el análisis de la apariencia física-artefactos de los personajes determina que éstos son utilizados principalmente para situar la acción y distinguir, de forma estereotipada, los personajes vinculados con Martini de aquellos otros que quedan fuera de este vínculo. Respecto al atractivo físico, los resultados obtenidos reflejan que, los personajes vinculados a la bebida Martini (el hombre Martini y las mujeres) responden todos ellos a los cánones de belleza actuales: hombre 
fuerte, delgado, con facciones muy marcadas y cuadradas, joven, atlético, se cuida tanto física como estéticamente (cejas depiladas, sin arrugas, con la piel cuidada, bien afeitado, bien vestido); mujer delgada, estilizada, maquillada, con facciones muy marcadas, ojos profundos, rostro expresivo. Los personajes vinculados al producto responden a las expectativas y a los prototipos establecidos culturalmente como físicamente atractivos.

El aspecto físico general de los personajes es utilizado para definir los roles que desempeñan los mismos de manera estereotipada. Los personajes "Martini” son jóvenes y atractivos, mientras que los personajes que se oponen a Martini son viejos, con arrugas y sin atractivo o contrarios a los cánones de belleza establecidos. Destaca el hecho de que los actores que están vinculados positivamente a la marca tienen todos unos labios muy carnosos y gruesos (calificados de sensuales, eróticos, atractivos, pasionales), mientras que los personajes con vínculos negativos presentan todos labios finos y delgados (asociados a personalidades frías, calculadoras y racionales).

Figura 2. Aspecto físico de los personajes analizados
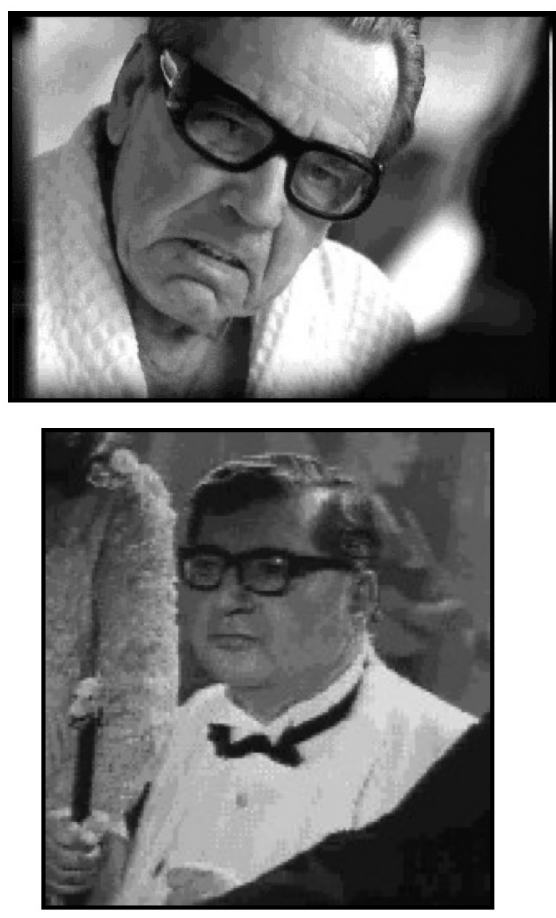
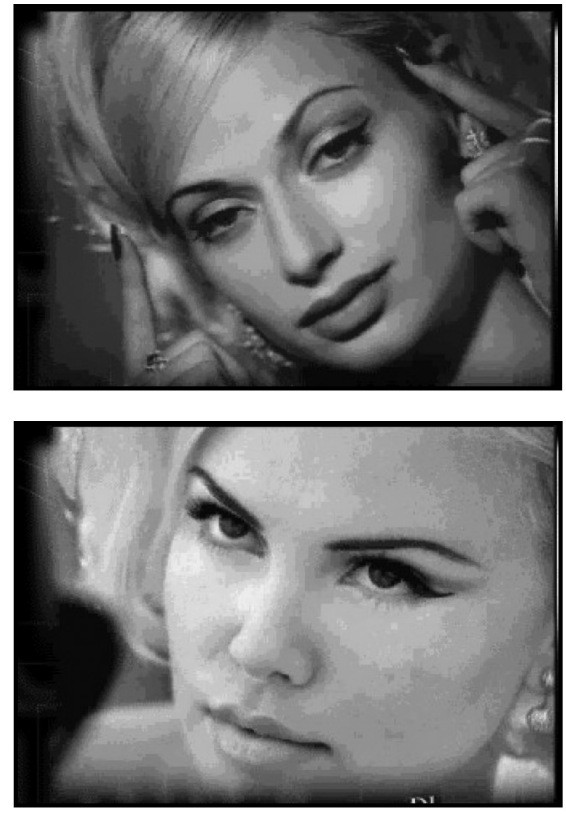

Fuente: Imágenes extraídas de los spots “El hombre Martini en la Riviera” y "El hombre Martini en el Casino” 
Existen también ciertas similitudes entre las figuras estereotipas de los protagonistas del cine negro americano (el gánster, el chico, la chica) con los personajes de Martini (el hombre poderoso, el chico Martini, la chica seducida); estereotipos a su vez reforzados por los ambientes en los que se enmarcan las historias de Martini (la Riviera, los Casinos -el juego era una de las principales tapaderas de los gánsteres-, los yates, el lujo, etc).

Esta estereotipación de los personajes no sólo viene establecida por la apariencia física y ambientación. También los artefactos que portan los personajes refuerzan esta distinción: gafas oscuras, modernas y estilizadas para el hombre Martini frente a gafas extravagantes, gruesas y transparentes de los otros personajes; trajes de colores oscuros para los personajes relacionados con Martini, frente a trajes o ropas claras de los personajes enfrentados a la marca. El color oscuro de los protagonistas relacionados con la marca simboliza lo misterioso, lo oculto, lo desconocido, que es como se caracteriza al hombre Martini, frente al blanco que estaría utilizado aquí como contrario al negro.

De los artefactos utilizados en los spots analizados destacan las gafas de sol que utiliza en todo momento el hombre Martini. No es normal que en los anuncios publicitarios los personajes que intervienen en ellos aparezcan con gafas de sol (a excepción de los anuncios correspondientes a marcas de este producto u ópticas). Culturalmente, se considera una falta de educación, la utilización de éstas en sitos cerrados. Sin embargo, el hombre Martini las lleva en todo momento (tanto en sitos abiertos como en cerrados). Además, ocultar la mirada tras unas gafas de sol puede ser interpretado como un intento de engaño, ya que no podemos saber hacia dónde está mirando el hombre Martini, aunque sí que se sugiere a través del lenguaje fílmico (encuadres, planos subjetivos, etc.) y la orientación del cuerpo y el rostro. Las gafas de sol mantienen el misterio que rodea al personaje. La importancia de este artefacto era tal que el actor que representaba el papel de hombre Martini tenía prohibido, por contrato, quitarse las gafas de sol en público.

\subsubsection{Loterías y Apuestas del Estado}

Loterías y Apuestas del Estado lanzó en el año 1998 una nueva campaña de publicidad para su producto "Lotería de Navidad" presentando al "hombre de la Lotería” (un nuevo estereotipo que buscaba representar e identificar a la suerte como un hombre con unas características físico-expresivas muy concretas). A través de películas en blanco y negro, con reminiscencias a épocas pasadas, la campaña proponía este nuevo y emblemático símbolo para plasmar algo invisible como es la suerte y lo lanzaba a través de una serie de spots que se emitían cada final de año. El "hombre de la Lotería" consiguió impactar en el público en poco tiempo, con escasas apariciones y sin mediar palabra.

La entidad pública apostó con esta campaña por una serie de anuncios que mostraran pequeñas historias dentro de un contexto dado (Navidad), en donde el protagonista (el hombre de la Lotería, representando a la suerte), al cruzarse en el camino de diversos personajes, influía positivamente en sus vidas. Aunque cada año, las historias representadas eran diferentes, el esteriotipo de la suerte se repetía siempre, dando así continuidad al conjunto de los spots. 
Se ha analizado la proxémica de aquellos planos que han resultado especialmente relevantes en algún aspecto relacionado con esta área de la comunicación no verbal. De un total de 48 planos del spot de la campaña "Lotería de Navidad 2005" fueron significativos para el estudio de esta área 18 de ellos. Siguiendo los estudios de Hall (1972, 1989) se ha analizado la comunicación proxémica en función del tipo de información que transmite. Principalmente, esta se centra en dos aspectos: la contextualización de las escenas y el tipo de relación que guardan los personajes entre sí.

Los planos de contextualización permiten la ubicación del espectador dentro de una escena concreta e informan del desarrollo de la historia publicitaria a través de la presentación de nuevos escenarios. Al principio del spot, los planos que se muestran describen la plaza de una ciudad en época navideña. A medida que el protagonista del spot (el "hombre de la Lotería") se va moviendo por este contexto, la proxémica informa de los nuevos escenarios que se van presentando. Tras estos primeros planos de contextualización, en la historia que se nos "narra" se produce un desplazamiento significativo tanto espacial (indicado a través de la proxémica) como temporal (indicado a través del cambio del blanco y negro al color); el traslado del "hombre de la Lotería" de una ciudad en un tiempo navideño pasado, cordial y armonioso, a una ciudad moderna, ruidosa y tensa. Es la aplicación de una observación de la proxémica de los actores, la que nos permite descubrir en el resto del anuncio tres micro-historias que va a contemplar el protagonista dentro de esta ciudad moderna: una estación pública (historia del taxista y el bebé), un edificio de oficinas (historia del guarda de seguridad y la mujer de la limpieza) y una calle comercial (historia de la niña y la jirafa).

Hemos podido analizar 6 planos que ofrecen información acerca del tipo de relación que se puede establecer entre los personajes que van apareciendo en la historia. Siguiendo los estudios de Hall (1972) la distancia que guardan los personajes en 4 de los planos estudiados se codifican como de "íntima alejada" (de 15 a $40 \mathrm{~cm}$.) lo cual comunica proximidad, confianza y afecto (amistad, matrimonio, familia, amor); además, en algunos casos estas implicaciones afectivas de la distancia se ven reforzadas por algún tipo de contacto físico entre los personajes. En otro plano la distancia es considerada como "íntima cercana" (menos de $15 \mathrm{~cm}$.) debido a la proximidad entre los personajes. La distancia mantenida puede quedar justificada por la postura corporal que adoptan, la cual comunica que se disponen a bailar un vals, y este tipo de baile necesita proximidad con la pareja y contacto físico. Sin embargo, por los planos mostrados anteriormente en el spot, las miradas de los personajes, sus roles y el contexto en el que se encuentran, sabemos que este baile es especial y que implica algo más que la mera actividad física.

Finalmente, en el último plano analizado, se observa una distancia entre los personajes codificada de "personal alejada" (más de $70 \mathrm{~cm}$.), también denominada distancia administrativa por ser la distancia propia de las relaciones impersonales profesionales o de conversaciones triviales de calle. Esta comunicación proxémica, unida a la información de contexto, nos indica que la relación que guardan los personajes de esta escena es formal-comercial (un taxista que espera que la mujer que ha llevado a la estación le pague). Gracias a esta información, quedan justificadas reacciones de los personajes como 
la sorpresa del taxista cuando la madre le hace entrega del bebé para buscar más fácilmente el monedero (no se ha establecido un nivel de confianza suficiente entre los personajes para este tipo de acciones).

Por último, hay que indicar que el protagonista del spot publicitario (el "hombre de la Lotería”), a pesar de ser el eje de presentación de todas las micro-historias y estar presente en todas ellas, siempre se mantiene distanciado de las mismas; distancias codificadas como "públicas" (tanto en su modo cercano, de 3.60 a 7.50 m., como alejado, 7.50 m. o más) ó "sociales" (tanto en su modo cercano, de 1.25 a $2.10 \mathrm{~m}$., como alejado, de 2.10 a $3.60 \mathrm{~m}$.). Parece que esta información proxémica da a entender que "la suerte", que simboliza el "hombre de la Lotería”, está presente en todas partes pero no se "casa" con nadie, no va unida a nadie. La suerte deambula e influye en los demás, pero ésta siempre anda sola (como el protagonista del spot).

La expresión facial ha sido analizada en 29 planos. Este es uno de los campos más investigados de la comunicación no verbal. Son varias las investigaciones que profundizan, codifican e investigan las mismas; sin embargo, las expresiones faciales consideradas como básicas por su fácil e universal codificación son las de sorpresa, miedo, cólera, disgusto, alegría/felicidad y tristeza. Ekman, Friesen y Tomkins (1971) abordan el estudio y la codificación de las expresiones faciales a través del análisis del rostro. Basándose en este estudio, se han observado y analizado las principales expresiones que aparecen en el spot de "Lotería de Navidad" y se han identificado diez: alegría/simpatía, seriedad, ternura/aprecio/amor, preocupación, sorpresa, expectativa, pensamiento/idea, curiosidad, ruego y agradecimiento.

Tabla II. Expresiones identificadas en el spot de Loterías y Apuestas del Estado

\begin{tabular}{|c|c|}
\hline Expresión & Número de veces identificada \\
\hline Alegría/Felicidad/Simpatía & 19 \\
\hline Seriedad & 4 \\
\hline Ternura/Aprecio/Amor & 4 \\
\hline Preocupación & 3 \\
\hline Sorpresa & 2 \\
\hline Expectativa & 2 \\
\hline Pensamiento/Idea & 2 \\
\hline Curiosidad & 1 \\
\hline Ruego & 1 \\
\hline Agradecimiento & 1 \\
\hline
\end{tabular}

Fuente: Elaboración propia. 
Para el análisis de esta variable aplicada a la narrativa publicitaria audiovisual, hay que tener en cuenta que, tanto las situaciones como las historias mostradas en el spot son ficticias y que, por lo tanto, los personajes, sus expresiones y emociones, también lo son. En este sentido y tomando una reflexión de Knapp (1995:241) “en situaciones 'reales' una persona puede estar comunicando a los demás un estado particular, mientras que un actor sólo tratará de comunicar de la mejor forma posible, la emoción que se le ha pedido que represente".

Las expresiones faciales plasmadas en el spot de "Lotería de Navidad 2005" son expresiones trabajadas que buscan comunicar, de una forma directa y clara, una emoción o un estado de ánimo; pretendiendo así transmitir a través de la comunicación no verbal un mensaje claro, directo, de fácil comprensión y sencilla codificación. No es sorprendente pues, que la expresión más utilizada e identificada en el análisis se corresponda a una de las emociones básicas más conocidas y fáciles de interpretar: la alegría/felicidad/simpatía.

Al tratarse de un anuncio contextualizado en la época navideña (con las connotaciones que tradicionalmente este tiempo conlleva) y con un mensaje positivo ("Cada Navidad, tus sueños juegan a la Lotería. Que la suerte te acompañe"), tampoco extraña que el mayor número de expresiones faciales identificadas sean de carácter positivo o devengan en alguna acción positiva; lo cual también provoca que todo el anuncio quede envuelto en este satisfactorio ambiente.

Las expresiones faciales del spot, junto con la conducta visual, son las que llevan el mayor peso del hilo conductor de la historia que se "narra" y las que más información aportan acerca de lo que está ocurriendo (situaciones, sentimientos de los personajes, reacciones...).

El principal gesto analizado en esta ocasión ha sido el de "soplar" (al ser el gesto más característico que realiza el protagonista). En este gesto, los labios se contraen en forma de "u" y se realiza, o se hace ademán, de expulsar aire a través de la boca. Se puede observar este gesto en el plano final del spot cuando el "hombre de la Lotería" se acerca la mano a la boca y sopla sobre ella, lanzando sobre el espectador toda una serie de números de la suerte dentro de bolas (burbujas) transparentes. 
Figura 3. El gesto del "hombre de la Lotería”

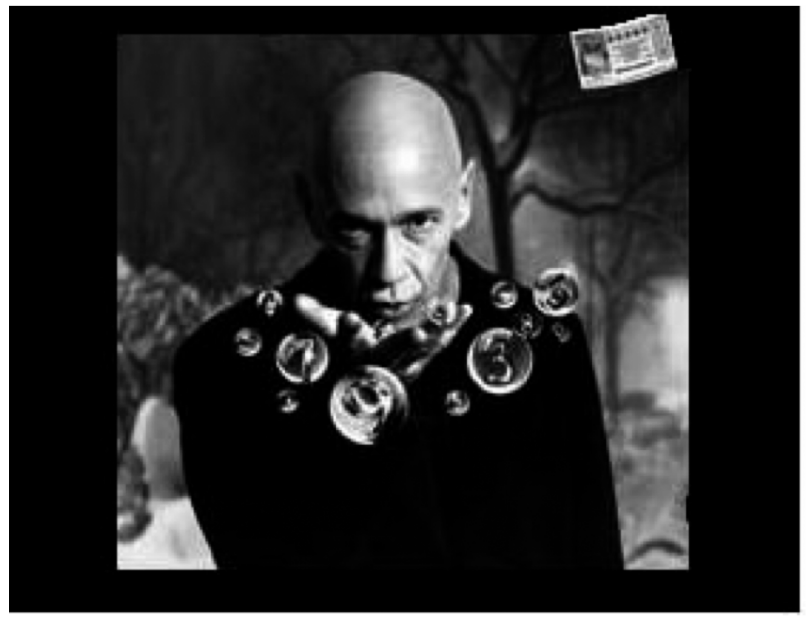

Fuente: Imagen extraída del spot de “Lotería de Navidad 2005”

De los 48 planos que constituyen el spot, se han analizado el aspecto físico y los artefactos en 12 de ellos. Estas dos variables se han considerado conjuntamente ya que los artefactos influyen en el aspecto físico de los personajes mostrados, además de caracterizarlos y delimitar el rol y la significación de los mismos. Los resultados obtenidos sobre el aspecto físico de los personajes reflejan que: los personajes masculinos que presentan una edad más avanzada (más de 40 años) son mostrados con una complexión mesomorfa pero con cierto grado de endomorfismo (excepto el protagonista, el "hombre de la lotería"), sus rostros no responden a los cánones de belleza actualmente establecidos, pero son físicamente agradables (el padre del niño del tiovivo y el taxista); los hombres más jóvenes (menos de 40 años) son presentados con una complexión corporal mesomorfa y con mayor atractivo al cuidarse tanto física como estéticamente; barba arreglada y de corte moderno, cejas perfiladas (no pobladas), sin arrugas visibles, etc. (guarda de seguridad).

Las mujeres presentan, en todos los casos, una complexión corporal mesomorfa con cierto grado de ectomorfismo, lo cual vendría a responder al tipo de modelo corporal femenino preferido en los spots publicitarios. Sus características faciales las hacen más visualmente agradables que atractivas: rostros finos, cuidados, expresivos (las dos amigas cogidas del brazo, la madre del niño del tiovivo, la mujer que paga al taxista, la mujer de la limpieza, la madre de la niña).

La mayor parte de los artefactos analizados en el spot son utilizados para la caracterización del contexto más que para definir o dotar de un cierto valor o significado a los personajes. Destacan las ropas de invierno (chaquetas, abrigos, capas, 
gabardinas) y sus complementos (bufandas, gorros de lana, guantes) como artefactos que refuerzan el contexto de la época navideña, tradicionalmente plasmada en un tiempo frío y nevado. Estas ropas y complementos son portadas por todos los personajes presentados en el spot en escenas de calle.

Los planos correspondientes a la micro-historia del edificio de oficinas, introducen a dos personajes que no llevan ninguna ropa de abrigo e incluso visten con manga corta (guarda de seguridad y mujer de la limpieza). Esta indumentaria queda justificada por el contexto, ya que se trata del interior de un edificio y el espectador puede presuponer que este está dotado de calefacción. Los artefactos aquí juegan un papel esencial a la hora de caracterizar y delimitar el rol de los personajes; se trata de dos uniformes, lo cual determina la asignación de una profesión concreta para cada uno: guarda de seguridad para él (camisa con escudos cosidos y placa de identificación en el pecho) y mujer de la limpieza para ella (bata azul, zapatillas y manejando una aspiradora).

De los artefactos utilizados en el spot analizado, cabe destacar uno que juega un papel esencial a la hora de definir e identificar los diferentes tiempos (pasado y presente) en los que se desarrolla la historia publicitaria: el sombrero. La utilización del blanco y negro, unida a la presencia del sombrero en todos los personajes de la primera parte del anuncio, evoca reminiscencias de tiempos pasados que ubican perfectamente al espectador dentro de la historia. La aparición del color, el corte musical y la ausencia de este artefacto en los siguientes personajes, informan al receptor del anuncio de una transición temporal que les sitúa ahora en un tiempo más moderno y actual. Se podría decir que el sombrero ayuda también a "narrar" parte de la historia publicitaria.

El protagonista de la campaña de "Lotería de Navidad 2005" es un hombre con unas características físico-expresivas muy peculiares que han conseguido, ya no sólo impactar en la audiencia, sino identificar y estereotipar a "la suerte" (desde la perspectiva publicitaria) con el aspecto físico de este personaje.

El “hombre de la Lotería” presenta una edad que rondará los 45 años, mesomorfo de complexión fuerte, alto y de porte estilizado. Su rostro es ovalado, con labios finos, nariz ancha, facciones muy marcadas pero sin llegar a ser duras, ojos no muy grandes, mirada expresiva y calvo (la característica que más trascendió y caló socialmente). Cabe decir aquí que, en realidad, Clive Arrindel (actor que representaba el papel del "hombre de la Lotería") no era calvo, sino que se rasuraba todos los años para el rodaje del spot. Aunque la ausencia de pelo no es algo extraño en la actualidad, sigue llamando la atención y posee connotaciones popularmente aceptadas como la de ser "interesante". Esta peculiaridad física, unida al porte marcial y misterioso del actor, convirtió a Clive Arrindel en el "calvo de la Lotería”.

Físicamente no responde al canon de belleza occidental establecido, pero sí que posee un físico con gran magnetismo y atractivo, que transmite cierto halo de misterio y curiosidad, y que responde a la perfección al significante que pretende simbolizar: la suerte, la fortuna. 
Siempre va vestido completamente de negro, con un suéter fino bajo un abrigo largo y pantalones a juego. El color destaca sobre los fondos navideños (blancos y nevados) que contextualizan la mayor parte de las imágenes mostradas, aunque podría chocar con la concepción cromática cultural que se podría tener de la suerte; la "suerte negra" es "mala suerte" en la cultura occidental. Sin embargo, esta contraposición del color de la ropa con la simbología del personaje no parece haber transcendido. El público considera su atuendo como atemporal, serio, sobrio pero con personalidad y lo vincula positivamente al personaje del "hombre de la Lotería”, ya que el color oscuro simboliza también lo misterioso, lo oculto, lo desconocido, tal y como se caracteriza al factor suerte.

Para mantener y no romper este halo de misterio que se había forjado sobre el personaje de "el hombre de la Lotería", el actor británico, Clive Arrindel, tenía un contrato de exclusividad con la agencia de publicidad y con la Organización Nacional de Loterías por el que no le estaba permitido hablar en público y no podía anunciar ningún otro producto.

El análisis y estudio de la proxémica, la expresión facial y el aspecto físico-artefactos en los spots de Martini y de Lotería y Apuestas del Estado, muestra cómo el peso argumental-persuasivo de estos se centra fundamentalmente en los componentes no verbales de la realidad analizados, constituyendo toda una estrategia creativa de narración y connotación estudiada y muy elaborada (falsa espontaneidad de los códigos no verbales de la realidad).

Se destaca el hecho de que la comunicación no verbal tiene capacidad suficiente para "narrar" toda una historia (con su planteamiento-nudo-desenlace), pudiendo representar acciones complejas y aportando el sentido final/global al anuncio. Los spots publicitarios, entendidos como "micro-historias" condensadas en unos segundos, obtienen de la comunicación no verbal una gran capacidad de transmisión de ideas, valores, planteamientos y conductas.

\section{Conclusiones}

La comunicación no verbal forma parte del discurso publicitario constituyendo un lenguaje propio, lo suficientemente codificado en algunos casos, como para estudiarlo de forma sistemática y con mayor precisión. La publicidad, al utilizar personajes en la mayoría de sus anuncios, necesita tener en cuenta todos los elementos propios de los códigos no verbales de la realidad, ya que desde el momento en que haya una persona, hombre o mujer, en escena, la comunicación no verbal empieza a surtir efecto. Por tanto, el estudio de la comunicación no verbal humana es esencial para la eficacia de la comunicación publicitaria.

El objetivo principal de la publicidad es persuadir y, para ello, necesita que todo lo que aparezca en sus mensajes esté estudiado y trabajado para conseguir dotar a la marca/producto anunciado de valores con los que el anunciante se va a posicionar, identificar y diferenciar. El análisis exhaustivo de expresiones, gestos, aspecto físico de los personajes... constituye una pieza clave en este objetivo; sin embargo la preparación de estos elementos para el discurso publicitario, rompe 
el carácter espontáneo propio de la comunicación no verbal humana. Esta "espontaneidad y naturalidad controlada" responde pues, mayoritariamente, a objetivos de persuasión, connotación y personalidad, que la publicidad busca conseguir a través de sus mensajes.

La capacidad informativo-persuasivo-intencional de la comunicación no verbal en los anuncios publicitarios, debería ser un componente a analizar, investigar y valorar, aportando con ello mayor riqueza al estudio de las piezas publicitarias, incluso pudiendo arrojar claves sobre el éxito o fracaso de las mismas o sobre su influencia en aspectos ajenos a su vertiente económica (ventas), como pueden ser sus repercusiones sociales, psicológicas, físicas ó educativas.

Estudiando estos componentes no verbales de la comunicación publicitaria, su utilización, funciones, intenciones e interpretaciones, podemos llegar a estimar la capacidad comunicativa y la influencia de esta en el proceso de significancia final del mensaje publicitario. Este análisis ayudaría al enriquecimiento de la investigación del fenómeno publicitario en todas las disciplinas que lo abordan (psicología, sociología, economía, lingüística, mercadotecnia, etc.) así como en el estudio y comprensión global del sentido y significados denotados y connotados que se desprenden del mensaje publicitario. "En la actualidad, la comunicación entraña un complejo proceso en el que los códigos verbales estrictamente lingüísticos han dejado de desempeñar el papel exclusivo en el discurso y comparten su valor en la construcción del sentido con otros códigos no verbales, especialmente icónicos y multimedia" (Prado, 2001: 22).

Además, las aportaciones de una investigación de esta índole en el mundo docente facilitarían las pautas para la conformación de una competencia comunicativa más integral en la que se pudiera abordar el estudio del mensaje publicitario y sus componentes, ya no sólo desde la perspectiva de saber cómo se hace el anuncio y por qué, sino también analizando para qué se hace, cómo persuaden y seducen sus elementos, cómo se imbrican y complementan unos a otros, qué valores connotados están "vendiendo" y cómo los están transmitiendo, qué ideales promueven, qué implican y qué grado de influencia pueden llegar a tener. Esta visión de la publicidad permitiría poder desarrollar y fomentar una mirada publicitaria crítica producto de una nueva alfabetización basada en los nuevos medios y en los nuevos lenguajes que se están desarrollando en el seno de una sociedad cada vez más de la comunicación, más del consumo y más multimedia.

Finalmente, y como ya hemos indicado anteriormente, queremos volver a remarcar que la pretensión de este trabajo no es la de extraer conclusiones categóricas y extrapolables a nivel genérico, ya que somos conscientes de la escasez de la muestra y de la necesidad de continuar ampliando y enriqueciendo el corpus de análisis. Pero consideramos que los ejemplos seleccionados son, al menos, significativos e ilustrativos de la capacidad comunicativa de los componentes no verbales en los anuncios publicitarios y de la importancia que estos códigos pueden desempeñar en la eficacia y el éxito de una campaña. Por tanto, nuestro principal objetivo al finalizar este artículo sería el que este llegara a avivar y a potenciar el estudio en profundidad de los códigos no verbales en el mensaje publicitario. 


\section{Referencias bibliográficas}

Bassat, L. (1993): El libro rojo de la publicidad. Barcelona: Folio.

Batenson, G. et al. (1994): La nueva comunicación. Barcelona: Kairós.

Bianchi, C. (2011): “Semiotic approaches to advertising texts and strategies: Narrative, passion, marketing”, Semiotica, 183, pp. 243-271.

Birdwhistell, R. (1979): El lenguaje de la expresión corporal. Barcelona: Gustavo Gili.

Cassetti, F.; Di Chio, F. (1999): Análisis de la televisión. Instrumentos, métodos y prácticas de investigación. Barcelona: Paidós.

Cebrián, M. (2001): “Aprender a ver y analizar la información audiovisual”, Comunicar, 17, pp. 15-20.

De los Ángeles, J. (1996): Creatividad publicitaria. Pamplona: Eunsa.

Eco, U. (1978): La estructura ausente. Introducción a la semiótica. Barcelona: Lumen.

Eguizábal, R.; Caro, A. (1996): Medición, investigación e información de la publicidad. Madrid: Comunicación 2000.

Ekman, P.; Friesen, W. V. (1969): “The repertoire of nonverbal behavior: categories, origins, usage and coding”, Semiótica, 1, pp. 62-98.

Ekman, P.; Friesen, W. V; Tomkins, S. S. (1971): "Facial Affect Scoring Technique: a first validity study”, Semiótica, 3, pp. 37-58.

Fanjul, C. (2005): La importancia de la comunicación no verbal dentro de la publicidad audiovisual, como recurso y como estrategia publicitaria diferencial. Castellón: Trabajo de investigación inédito, Universitat Jaume I.

- (2008): Vigorexia: una mirada desde la publicidad. Madrid: Fragua.

García, F. (2003): “Posibilidades creativas de la imagen”, Icono 14, 2, pp. 9-25.

Gómez, J. (2003): Lo ausente como discurso: elipsis y fuerza de campo en el texto cinematográfico. Valencia: Universitat de Valencia.

Gubern, R. (1998): Mensajes icónicos en la cultura de masas. Barcelona: Lumen.

Hall, E. T. (1966): The hidden dimension. Nueva York: Doubleday \& Co.

- (1972): La dimensión oculta. Enfoque antropológico del uso del espacio. Madrid: IEAL.

- (1989): El lenguaje silencioso. Madrid: Alianza Editorial.

Joly, M. (1999): Introducción al análisis de la imagen. Buenos Aires: La Marca. 
Knapp, M. L. (1995): La comunicación no verbal. El cuerpo y el entorno. Barcelona: Paidós.

Leduc, R. (1986): Principios y práctica de la publicidad. Bilbao: Deusto.

León, J. L. (2001): Mitoanálisis de la publicidad. Barcelona: Ariel.

Lorente, J. (1991): Casi todo lo que sé de publicidad. Barcelona: Folio.

Maciá Mercadé, J. (2000): Comunicación persuasiva para la sociedad de la información. Madrid: Universitas.

Marín, F; Armentia, J. I.; Ganzábal, M. (2010): “La publicidad en las revistas femeninas y masculinas: reflejo de los estereotipos de género", Doxa, 10, pp. 35-56.

Martín, M.; Navarro, M. (2009): “La comunicación como categoría básica de lo social: una aproximación a la Escuela de pensamiento social de la Universidad de Chicago", Doxa, 8, pp. 13-24.

Mehrabian, A. (1971): Silent Messages. Belmont: Wadsworth.

Meo-Zilio, G.; Mejía, S. (1980): Diccionario de gestos. Bogotá: Imprenta Patriótica del Instituto Caro y Cuervo.

Metz, C. (2001): El significante imaginario. Barcelona: Paidós.

Mills, J.; Aronson, E. (1965): “Opinion change as a function of the communicator's attractiveness and desire to influence”, Journal of Personality and Social Psychology, 1(2), pp. 73-77.

Moragas, M. (1976): Semiótica y comunicación. Barcelona: Península.

Peirce, C. S. (1986): La ciencia de la semiótica. Buenos Aires: Nueva Visión.

Péninou, G. (1976): Semiótica de la publicidad. Barcelona: Gustavo Gili.

Pérez Gauli, J. C. (2000): El cuerpo en venta. Madrid: Cátedra.

Pérez Ruiz, M. A. (1979): El mensaje publicitario y sus lenguajes. Madrid: Instituto Nacional de Publicidad.

- (1985): Funciones comunicativo-persuasivas del rostro en la comunicación publicitaria. Barcelona: Tesis doctoral, Universidad Autónoma de Barcelona.

- Piñuel, J. L.; Gaitán, J. A. (1995): Metodología General. Conocimiento científico e investigación en la comunicación social. Madrid: Síntesis.

Prado, J. (2001): “La competencia comunicativa en el entorno tecnológico: desafío para la enseñanza”, Comunicar, 17, pp. 21-30.

Rodríguez, R.; Mora, K. (2002): Frankenstein y el cirujano plástico: una guía multimedia de semiótica de la publicidad. Alicante: Universidad de Alicante.

Sheldon, W. H. (1954): Atlas of man: a guide for somatyping the adult male at all ages. Nueva York: Harper \& Row.

96 | n 14 | doxa.comunicación 
Tornero, J. M. (1982): La semiótica de la publicidad. Barcelona: Mitre.

Wainwright, G. R. (1991): El lenguaje del cuerpo. Madrid: Pirámide.

Watzlawick, P.; Beavin, J.; Jackson, D. (2002): Teoría de la Comunicación Humana. Barcelona: Herder. 